\title{
Corrosion Inhibition Effect of Phosphate on Fine-grain High- strength Reinforcement in Simulated Concrete Pore Solutions with Carbonation and Chloride-intrusion
}

\author{
Bilan Lin ${ }^{1,2, *}$, Chaonong Liu ${ }^{1}$, Zan Luo ${ }^{1}$, Jieda $\mathrm{Li}^{1}$, Shan Wang ${ }^{1}$, Yuye Xu ${ }^{3}$ \\ ${ }^{1}$ School of Material Science and Engineering, Xiamen University of Technology, Xiamen 361024, \\ China \\ ${ }^{2}$ Key Laboratory of Functional Materials and Applications of Fujian Province, Xiamen 361024, China \\ ${ }^{3}$ College of Civil Engineering, Huaqiao University, Xiamen, Fujian 361021, China \\ *E-mail: $\underline{\text { linbilan@xmut.edu.cn }}$
}

doi: $10.20964 / 2017.03 .40$

Received: 16 December 2016 / Accepted: 12 January 2017 / Published: 12 February 2017

The passivation performance of fine-grain high-strength (HRBF500) reinforcement in simulated concrete pore (SCP) solutions was seriously impaired by carbonation and chloride-intrusion of concrete. Phosphate was used as corrosion inhibitor and the effect of $\left[\mathrm{PO}_{4}{ }^{3-}\right] /\left[\mathrm{Cl}^{-}\right]$ratio was investigated. The corrosion properties of HRBF500 reinforcement were investigated via potentiodynamic polarization, electrochemical impedance spectroscopy (EIS) and scanning electron microscopy (SEM). The semiconductor features of the corrosion products were studied according to Mott-Schottky theory. The results show that the anodic corrosion process of HRBF500 reinforcement can be greatly inhibited by sufficient high phosphate concentration, while the influence on the cathodic process is generally smaller. The corrosion products on HRBF500 reinforcement manifest as n-type semiconductors. With the increase in $\left[\mathrm{PO}_{4}{ }^{3-}\right] /\left[\mathrm{Cl}^{-}\right]$ratio, the donor concentration $N_{\mathrm{D}}$ decreases, while the efficiency of corrosion protection first increases considerably and then tends to be stable. The compactness of the corrosion products is also enhanced. For the case with $0.6 \mathrm{~mol} \cdot \mathrm{L}^{-1} \mathrm{Cl}^{-}$but without carbonation $(\mathrm{pH} \approx 12.5)$, the corrosion current density $i_{\text {cor }}$ decreases from 13.2 to $0.40 \mu \mathrm{A} \cdot \mathrm{cm}^{-2}$ at $\left[\mathrm{PO}_{4}{ }^{3-}\right] /\left[\mathrm{Cl}^{-}\right]=1.0$, while for $\mathrm{pH}=10.5$ and $\left[\mathrm{Cl}^{-}\right]=0.3 \mathrm{~mol} \cdot \mathrm{L}^{-1}$ (more aggressive), $i_{\text {cor }}$ is still up to $0.80 \mu \mathrm{A} \cdot \mathrm{cm}^{-2}$ and decreases to $0.42 \mu \mathrm{A} \cdot \mathrm{cm}^{-2}$ at $\left[\mathrm{PO}_{4}{ }^{3-}\right] /\left[\mathrm{Cl}^{-}\right]=4.0$. Therefore, to obtain better corrosion protection under the combined action of carbonation and chloride-intrusion, a higher phosphate concentration is required.

Keywords: Reinforcement; Fine grain; Corrosion; Simulated concrete pore solution; Phosphate FULL TEXT 
(C) 2017 The Authors. Published by ESG (www.electrochemsci.org). This article is an open access article distributed under the terms and conditions of the Creative Commons Attribution license (http://creativecommons.org/licenses/by/4.0/). 